\title{
Identification of genomic biomarkers for anthracycline-induced cardiotoxicity in human iPSC-derived cardiomyocytes: an in vitro repeated exposure toxicity approach for safety assessment
}

\author{
Umesh Chaudhari $^{1} \cdot$ Harshal Nemade $^{1} \cdot$ Vilas Wagh $^{1} \cdot$ John Antonydas Gaspar ${ }^{1}$. \\ James K. Ellis ${ }^{2} \cdot$ Sureshkumar Perumal Srinivasan $^{1} \cdot$ Dimitry Spitkovski $^{1}$ • \\ Filomain Nguemo $^{1} \cdot$ Jochem Louisse $^{3} \cdot$ Susanne Bremer $^{3} \cdot$ Jürgen Hescheler $^{1}$. \\ Hector C. Keun ${ }^{2} \cdot$ Jan G. Hengstler $^{4} \cdot$ Agapios Sachinidis $^{1}$
}

Received: 16 August 2015 / Accepted: 20 October 2015 / Published online: 4 November 2015

(C) The Author(s) 2015. This article is published with open access at Springerlink.com

\begin{abstract}
The currently available techniques for the safety evaluation of candidate drugs are usually cost-intensive and time-consuming and are often insufficient to predict human relevant cardiotoxicity. The purpose of this study was to develop an in vitro repeated exposure toxicity methodology allowing the identification of predictive genomics biomarkers of functional relevance for drug-induced cardiotoxicity in human induced pluripotent stem cell-derived cardiomyocytes (hiPSC-CMs). The hiPSC-CMs were incubated with $156 \mathrm{nM}$ doxorubicin, which is a well-characterized cardiotoxicant, for 2 or 6 days followed by washout of the test compound and further incubation in compound-free culture medium until day 14 after the onset of exposure. An xCELLigence Real-Time Cell Analyser was used to monitor doxorubicin-induced cytotoxicity while also monitoring functional alterations of cardiomyocytes by counting of the beating frequency of cardiomyocytes. Unlike single exposure, repeated doxorubicin exposure resulted in
\end{abstract}

Electronic supplementary material The online version of this article (doi:10.1007/s00204-015-1623-5) contains supplementary material, which is available to authorized users.

Agapios Sachinidis

a.sachinidis@uni-koeln.de

1 Institute of Neurophysiology and Center for Molecular Medicine Cologne (CMMC), University of Cologne, Robert-Koch-Str. 39, 50931 Cologne, NRW, Germany

2 Biomolecular Medicine, Department of Surgery and Cancer, Imperial College London, London, UK

3 Institute for Health and Consumer Protection, Joint Research Centre, European Commission, Ispra, Italy

4 Leibniz Research Centre for Working Environment and Human Factors at the Technical University of Dortmund (IfADo), 44139 Dortmund, Germany long-term arrhythmic beating in hiPSC-CMs accompanied by significant cytotoxicity. Global gene expression changes were studied using microarrays and bioinformatics tools. Analysis of the transcriptomic data revealed early expression signatures of genes involved in formation of sarcomeric structures, regulation of ion homeostasis and induction of apoptosis. Eighty-four significantly deregulated genes related to cardiac functions, stress and apoptosis were validated using real-time PCR. The expression of the 84 genes was further studied by real-time PCR in hiPSC-CMs incubated with daunorubicin and mitoxantrone, further anthracycline family members that are also known to induce cardiotoxicity. A panel of 35 genes was deregulated by all three anthracycline family members and can therefore be expected to predict the cardiotoxicity of compounds acting by similar mechanisms as doxorubicin, daunorubicin or mitoxantrone. The identified gene panel can be applied in the safety assessment of novel drug candidates as well as available therapeutics to identify compounds that may cause cardiotoxicity.

Keywords Cardiotoxicity - Human stem cells derived cardiomyocytes $\cdot$ Heart failure $\cdot$ Transcriptomics $\cdot$ Genomic biomarkers $\cdot$ In vitro test system $\cdot$ Safety assessment

\section{Introduction}

Drug-induced cardiotoxicity is a major safety issue and has to be considered during drug development. Various in vivo and in vitro assays have been developed to assess the adverse effect of lead compounds on cardiac functions. Due to interspecies physiological differences, these assays often do not correctly predict the actual adverse effects of drug candidates on the human heart. Moreover, traditional 
approaches to toxicological testing involve extensive animal studies, thus making testing costly and time-consuming. Although primate and human primary cardiomyocytes represent highly relevant cell systems, their use is limited by ethical reasons and difficult availability (Anson et al. 2011). Above all, the pharmaceutical industry is struggling with the costly withdrawal of drugs from the market due to toxic effects, often related to cardiotoxicity (Tafuri et al. 2013). Therefore, there is an urgent need for the development of a sensitive, robust and clinically relevant in vitro system with cardiomyocytes for efficacy and safety assessment.

Human embryonic stem cells (hESCs) and human induced pluripotent stem cell (hiPSC)-derived cardiomyocytes have a high physiological relevance and show typical drug-induced changes in electrophysiological properties (Caspi et al. 2009; Reppel et al. 2005; He et al. 2003). Reproducible and large-scale production of highly purified $\mathrm{hESCs} / \mathrm{hiPSC}$-derived cardiomyocytes (hESC-CMs/hiPSC$\mathrm{CMs}$ ) makes them an attractive source for human cardiotoxicity tests. It is expected that human cardiomyocytes will increase the predictive ability of the adverse effects of potential drugs in humans and may replace or reduce cardiac safety assessment assays based on animal-derived primary cardiomyocytes or cardiac ion channel overexpressing cell lines (Steel et al. 2009).

Among anti-cancer drugs, anthracycline family members such as doxorubicin, daunorubicin and mitoxantrone are known to induce cardiotoxicity (Menna et al. 2012; Paul et al. 2007). Multiple mechanisms such as free radical formation, lipid peroxidation and DNA damage have been proposed to explain the cardiotoxicity of anthracyclines. Additionally, interactions of anthracyclines with the DNA-topoisomerase complex or directly with DNA by intercalation result in disturbances in DNA replication and transcription and have been extensively studied (Minotti et al. 2004). Dose-dependent cardiotoxicity of anthracyclines limits their therapeutic application. Drugs that do not compromise the electrophysiology of the heart can also be cardiotoxic by directly damaging cardiomyocytes at both the subcellular and molecular levels via the formation of reactive oxygen species, DNA damage, mitochondrial damage, apoptosis or disturbed molecular signalling events. Elevated levels of cardiac troponin I (cTnI) and cardiac troponin $\mathrm{T}$ (cTnT) in blood correlate well with myocardial injury and act as critical plasma biomarkers for the diagnosis of cardiac damage in clinical and preclinical studies (Babuin and Jaffe 2005; O'Brien 2008; Tonomura et al. 2009). However, high levels of these biomarkers occur only after cardiac damage and can be detected for only a few hours after myocardial infarction and cardiotoxic drug treatment. To avoid drug-induced cardiotoxicity in the future, there is an urgent need to develop sensitive and reliable methods to detect or predict early cardiotoxic events.

In the present study, well-characterized hiPSC-CMs were used as an in vitro system of cardiotoxicity in combination with transcriptomics. Among the anthracyclines, doxorubicin is one of the most successful agents for solid and haematological malignancies in both children and adults. Doxorubicin has been extensively studied in a variety of preclinical models and clinical phases. Here, we developed a methodology allowing single and repeated chronic exposures of human cardiomyocytes to doxorubicin $(156 \mathrm{nM})$. The cardiotoxic effects of doxorubicin were monitored by real-time counting of the beating activity and cytotoxicity. Moreover, global gene expression changes were studied using a transcriptomic approach. Doxorubicin-deregulated expression signature of genes was further analysed in a follow-up study using daunorubicin and mitoxantrone, which also belong to the anthracycline family. Our study demonstrates that the integrative use of the xCELLigence Real-Time Cell Analyser (RTCA) cardio system and toxicogenomics offers a methodology to identify cardiotoxic compounds.

\section{Materials and methods}

\section{Cardiomyocyte cell culture}

All experiments were performed with purified human iCell Cardiomyocytes ${ }^{\circledR}$ (Cellular Dynamics International, Madison, WI, USA), which were derived from hiPSCs. The cardiomyocytes were supplied as a cryopreserved single cell suspension of a $98 \%$ pure population. The cardiomyocytes were a mixture of spontaneously electrically active atrial-, nodal- and ventricular-like myocytes. These cells exhibit typical biochemical, electrophysiological and mechanical characteristics of normal human heart cells with expected responses upon exposure to exogenous agents. Cryopreserved hiPSC-CMs were thawed in iCell cardiomyocytes plating medium (iCell-PM, Cellular Dynamics International, Madison, WI, USA) per the manufacturer's instructions. For functional studies, thawed cells were directly plated on a fibronectin-coated $\left(5 \mu \mathrm{g} / \mathrm{cm}^{2}, 2 \mathrm{~h}\right.$ at $\left.37{ }^{\circ} \mathrm{C}\right)$ E-plate Cardio 96 (ACEA Biosciences, San Diego, CA, USA) at approximately a $25 \times 10^{3}$ cells per well density using iCell-PM. For transcriptomic studies, thawed cells were plated on fibronectin-coated $\left(5 \mu \mathrm{g} / \mathrm{cm}^{2}, 2 \mathrm{~h}\right.$ at $\left.37{ }^{\circ} \mathrm{C}\right)$ 6 -well plates at a $0.4 \times 10^{6}$ per well cell density. Two days later, cells were maintained in iCell cardiomyocyte Maintenance Medium (iCell-MM, Cellular Dynamics International, Madison, WI, USA), with a fresh medium change after every 2 days. The cardiomyocytes were cultured in a standard cell culture incubator at $5 \% \mathrm{CO}_{2}, 37^{\circ} \mathrm{C}$. 


\section{Chemical compounds}

The $10 \mathrm{mM}$ stock solutions (in DMSO) of doxorubicin, daunorubicin and mitoxantrone were purchased from Selleck Chemicals. Stock solutions were stored as small volume aliquots in tightly sealed sterile tubes at $-80^{\circ} \mathrm{C}$. Drug dilutions were performed in pre-warmed $\left(37^{\circ} \mathrm{C}\right)$ iCell-MM prior to each drug exposure. Doxorubicin was used as the gold standard reference compound to develop experimental methodology.

\section{xCELLigence RTCA Cardio system}

The xCELLigence RTCA Cardio system (ACEA Biosciences, San Diego, CA, USA) is an impedance-based platform for monitoring the real-time beating function of cardiomyocytes. It was used to sensitively and quantitatively detect pro-arrhythmic drug effects on cardiac function and to measure cell viability in real time. Impedance measurements were monitored at regular time intervals. The amount of growth area covered in an E-plate Cardio 96 due to cell adhesion was represented as the Cell Index (CI). A high CI indicates more cell adhesion. Before cell plating, the background impedance of E-plate Cardio 96 (ACEA Biosciences, San Diego, CA, USA) was measured using iCell-PM ( $50 \mu \mathrm{l}$ per well). The raw data of cell viability, beating activity and the beating amplitude were acquired using the xCELLigence RTCA Cardio system and analysed using RTCA Cardio software version 1.0 (ACEA Biosciences, Inc, San Diego, CA, USA).

\section{RNA extraction}

Cell samples were homogenised with QIAzol lysis reagent (Qiagen, Hilden, Germany), and the total RNA was extracted and purified using the RNeasy mini kit (Qiagen, Hilden, Germany) according to the manufacturer's instructions. A Nanodrop (ND-1000, Thermo Fisher, Langenselbold, Germany) was used for RNA quantification and purity assessment. RNA integrity was confirmed using the Experion ${ }^{\mathrm{TM}}$ automated electrophoresis system (BioRad, Munich, Germany). Extracted RNA was subjected to human gene array processing using Affymetrix's kits, reagents and instrument setup.

\section{Microarray labelling and hybridization}

For microarray gene expression studies, $100 \mathrm{ng}$ of total RNA was used as a starting material. The total RNA samples were amplified and labelled using GeneChip $3^{\prime}$ IVT Express Kit per the manufacturer's instructions (Affymetrix, High Wycombe, UK). The amplified biotin-labelled RNA (aRNA) samples were purified using magnetic beads, and $15 \mu \mathrm{g}$ of aRNA was fragmented with fragmentation buffer per the manufacturer's instructions. Then, $12.5 \mu \mathrm{g}$ of fragmented aRNA was used to hybridize with Affymetrix Human Genome U133 plus 2.0 array along with the hybridization cocktail solution. For microarray hybridization, gene chips were placed in a GeneChip Hybridization Oven-645 (Affymetrix, High Wycombe, UK) for $16 \mathrm{~h}$ at $60 \mathrm{rpm}$ and $45^{\circ} \mathrm{C}$. After incubation, the arrays were washed and stained using the Affymetrix HSW kit on GeneChip Fluidics Station-450. The stained arrays were scanned with Affymetrix GeneChip Scanner-3000-7G, and image and quality control assessments were performed with Affymetrix GCOS software. The generated CEL files were used for further statistical analysis.

\section{Microarray statistical data analysis and functional annotation analysis}

Array raw data were quantile normalized using the RMA implementation of the R Affy package (Gautier et al. 2004). Differential expression was determined by the linear model implementation of the R Limma package (Minotti et al. 2004) followed by a Benjamini Hochberg multiple testing correction (1\% FDR). To specifically determine the perturbed transcripts, the expression level of transcripts in the doxorubicin (156 $\mathrm{nM}$ )-exposed cell samples was pairwise compared with that of day 2 and day 6 control cell samples, while doxorubicin washout cell sample transcripts were compared with day 14 control cell sample transcripts. The size of change was stated with a threshold value of fold change 2 in absolute scale. Choosing only significantly expressed probe sets, k-means cluster analysis was performed after transcript-wise normalization of signal values to a mean of 0 and an SD of 1 using Euclidean distance measurement and $k=6$, using the Cluster 3.0 tool from the Eisen laboratory (Eisen et al. 1999). To further investigate biological functions and the pathway involvement of genes, Database for Annotation, Visualization and Integrated Discovery (DAVID) was used for functional annotation and gene ontology (GO) clustering (Dennis et al. 2003). The GeneCards database was also used to investigate annotative information about genes and its relation to human cardiac disorders (Safran et al. 2010).

\section{mRNA expression analysis using $\mathbf{R T}^{2}$ profiler PCR arrays and real-time PCR}

Using 300-500 ng of total RNA, a genomic DNA elimination step and cDNA synthesis were performed with the $\mathrm{RT}^{2}$ First Strand kit (Qiagen, Hilden, Germany) according to the manufacturer's instructions. For quantitative comparison of mRNA levels, real-time PCR was performed using custom made RT $^{2}$ Profiler PCR array (96-well plate) (Qiagen, 
Hilden, Germany). This array contained 84 target genes, 5 housekeeping genes, 1 genomic DNA control, 3 reverse transcription controls and 3 positive PCR controls. Realtime PCR was performed using $\mathrm{RT}^{2} \mathrm{SYBR}^{\circledR}$ Green $\mathrm{ROX}^{\mathrm{TM}}$ qPCR master mix in an Applied Biosystems 7500 FAST Real-Time PCR System in accordance with the manufacturer's recommended thermal cycling conditions. The relative gene expression analysis was performed using the $2^{-\Delta \Delta \mathrm{Ct}}$ method with the RT ${ }^{2}$ PCR array data analysis online tool. Expression data were normalized using the geometric mean of 5 housekeeping genes-ACTB, B2M, GAPDH, HPRTI and RPLPO. A cut-off fold change value of 1.9 was set for significantly deregulated genes and later used to generate the gene list used for Venn diagram analysis.

\section{Immunostaining}

For immunocytochemistry analysis, control, doxorubicinexposed and washout iPSC-CMs were fixed with ice-cold $99 \%$ methanol (Roth, Karlsruhe, Germany) for $10 \mathrm{~min}$ at $-20{ }^{\circ} \mathrm{C}$. Then, cells were permeabilized with $0.3 \%$ Triton X-100 (Sigma-Aldrich, Steinheim, Germany) for $20 \mathrm{~min}$ at room temperature. Cells were blocked with $5 \%$ bovine serum albumin (Sigma, Steinheim, Germany) for $1 \mathrm{~h}$ at room temperature and incubated with anti-sarcomeric alpha actinin (Abcam, 1:200) and anti-cardiac troponin $\mathrm{T}$ (Abcam, 1:200) for $1 \mathrm{~h}$ at $37^{\circ} \mathrm{C}$. The cells were washed 3 times with phosphate-buffered saline (PBS) with $\mathrm{Ca}^{2+}$ and $\mathrm{Mg}^{2+}$ for 5 min. Primary antibodies were detected using species matched respective Alexa Fluor-488/568-conjugated secondary antibodies (Invitrogen, Darmstadt, Germany) with $1 \mathrm{~h}$ incubation at $37^{\circ} \mathrm{C}$. The cells were washed 3 times with PBS for 5 min and then mounted with Prolong® Gold anti-fade mount with DAPI (Invitrogen, Darmstadt, Germany). Cell images were taken with an Axiovert 200 fluorescence microscope and Axiovision 4.3 software (Carl Zeiss).

\section{Results}

\section{Experimental setup for single and repeated exposure}

Cryopreserved hiPSC-CMs were thawed, and after 4 days of cultivation, synchronously beating cardiomyocytes were exposed to doxorubicin according to the timeline schematically represented in Fig. 1. In brief, an experimental setup with single 2-day exposure periods to doxorubicin (156 nM, DOX-Day2) or three consecutive exposure periods to doxorubicin (DOX-Day6) (doxorubicin supplemental media refreshed every $48 \mathrm{~h}$ ) was applied. Until day 6, control cells were cultured in iCell-MM without doxorubicin but with DMSO as a solvent. Thereafter,

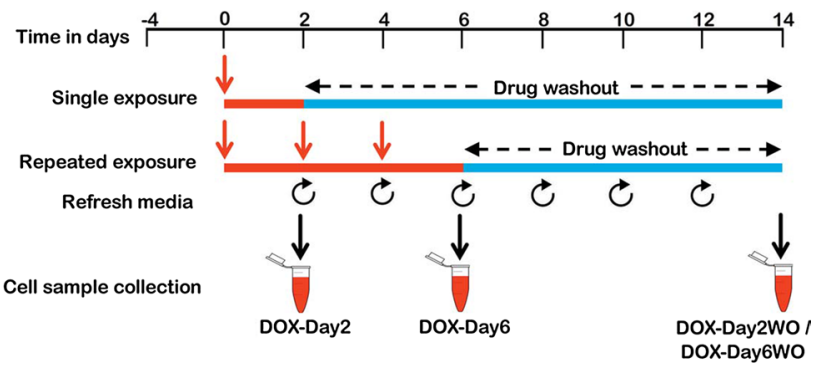

Fig. 1 Schematic representation and experimental setup of the in vitro cardiotoxicity test system. Four days post-cell plating, the synchronously beating hiPSC-CMs were exposed to drug/test compound either for a single 2-day exposure period (single exposure) or for 6 days, consisting of 3 culture medium changes every 2 days (repeated exposure). After exposure, the drug/test compound was washed out and the cells were further incubated until day 14. For functional studies, hiPSC-CMs were seeded in the E-plate Cardio 96 and the influence of drug/test compound on cardiomyocytes was monitored by the xCELLigence RTCA Cardio system. For transcriptomics studies, RNA of drug/test compound exposed cells was harvested at day 2 and day 6 , and after washout at day 2 and day 6, RNA samples were collected at day 14. Control cellular RNA samples were also harvested at the corresponding time points at day 2, 6 and 14

Fig. 2 Functional studies of doxorubicin-exposed hiPSC-CMs using the xCELLigence RTCA Cardio system. a The representative graph displays doxorubicin repeated exposure induced cytotoxicity showing a decrease in normalized Cell Index values. In the graph, DOXSE indicates doxorubicin single exposure and DOX-RE represents doxorubicin repeated exposure. Cell Index normalization was performed at a Cell Index value of 7.0. The numerical data represent means \pm standard deviations (SD) $(n=3)$. b Influence of single and repeated doxorubicin exposures $(156 \mathrm{nM})$ on cell density and morphology. The scale bar represents $50 \mu \mathrm{m}$. c Doxorubicin single and repeated exposures induced changes in \% beating rates. Basal beating rate of cardiomyocytes was from 25 to 32 per min at threshold 10. Data show the mean $\pm \mathrm{SD}(n=3)$. ***Indicates $p$ value $<0.005$. d Representative $12 \mathrm{~s}$ beating traces of hiPSC-CMs after doxorubicin single and repeated exposures and during drug washout. In each graph $Y$-axis represents normalized Cell Index (Nor. CI). Beating activity illustrates the development of arrhythmic beating upon repeated exposure and also in surviving cells after repeated exposure. e In contrast to single exposure, repeatedly exposed cells showed a significant decrease in beating amplitude when compared to control cells. Bar graph numerical values represent mean $\pm \operatorname{SD}(n=3)$. $* * *$ Indicates $p$ value $<0.005$

cardiomyocytes were further cultivated in doxorubicin-free iCell-MM till day 14 after the start of drug exposure. Culture medium changes were performed every 2 days. For the functional studies, beating and viability data from doxorubicin-exposed cardiomyocytes were obtained by the xCELLigence RTCA Cardio system. For transcriptomic studies, doxorubicin-exposed cardiomyocytes were harvested on day 2 and day 6 , respectively, whereas day 2 washout (DOX-Day2WO) and day 6 washout (DOX-Day6WO) cells were harvested on day 14. RNA isolated from the harvested cells was further analysed by gene array. The time frame 


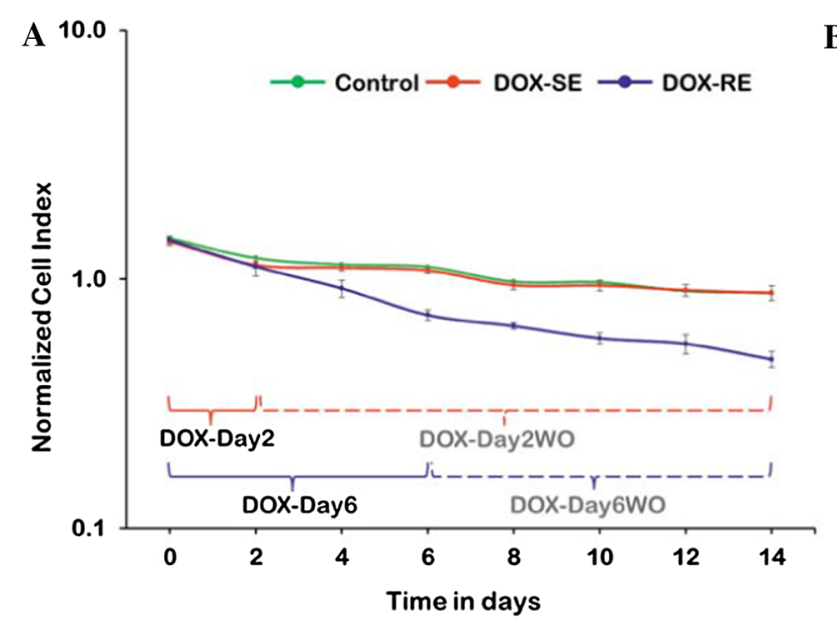

B
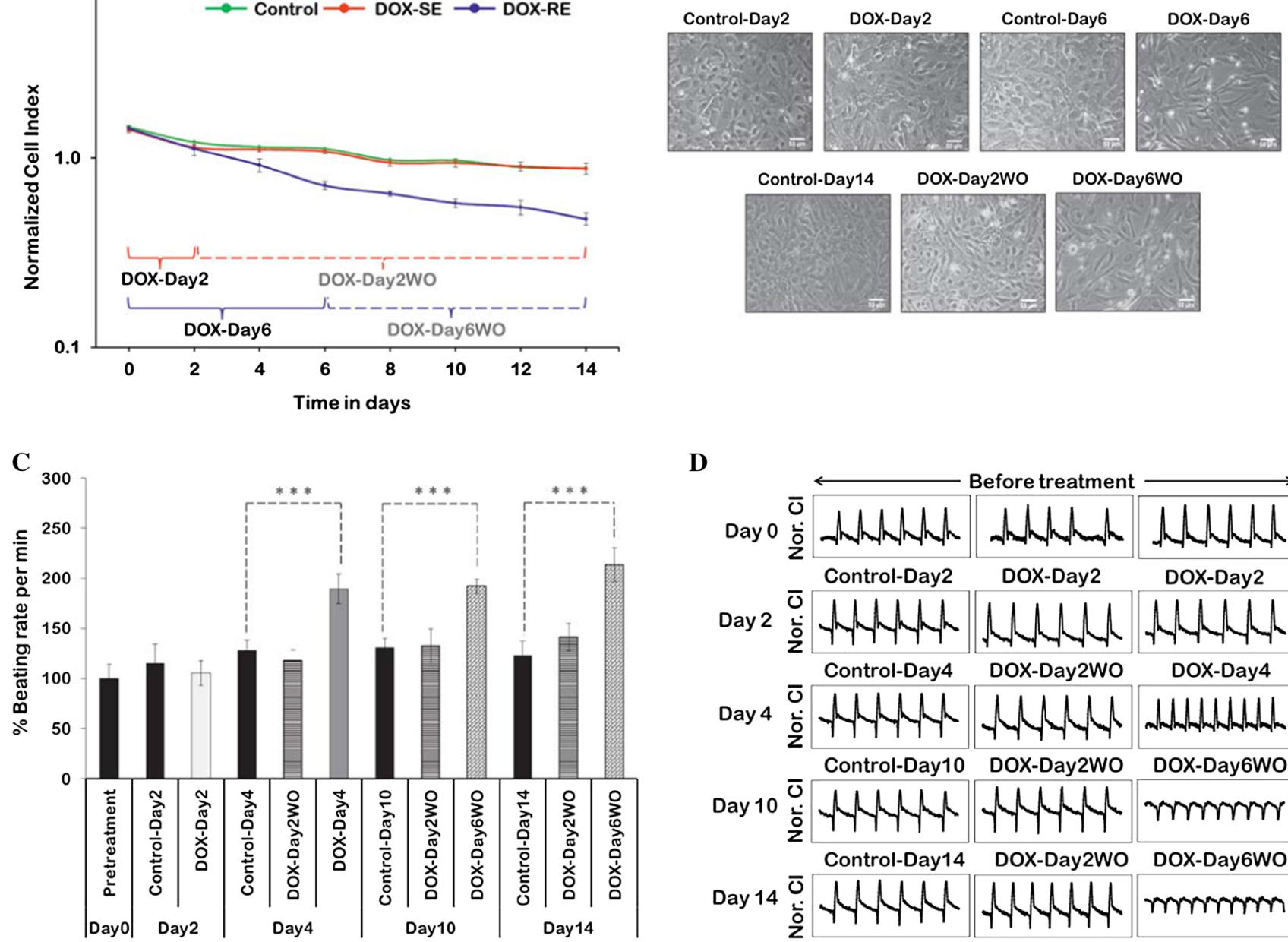

D

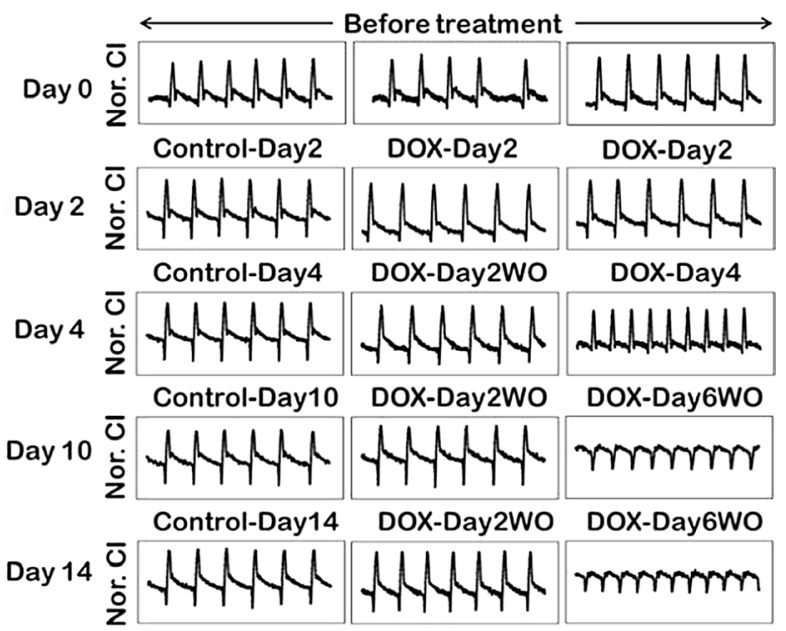

E

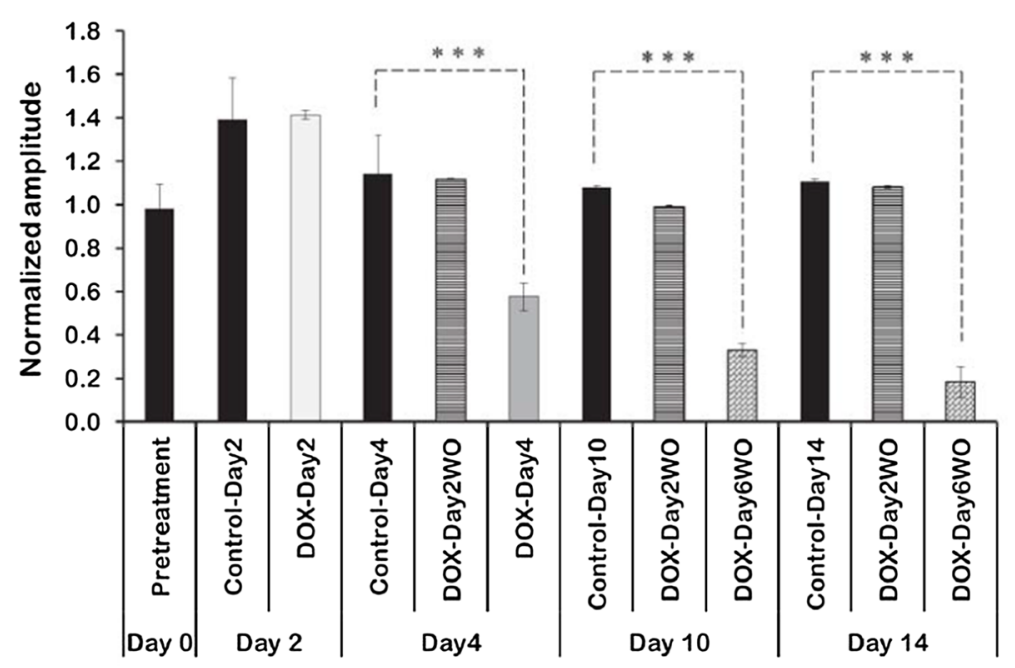

from day 4 and day 18 was chosen for the present study because hiPSC-CMs (after cell plating) can be cultured in an E-plate cardio 96 until day 18-19 without losing cell viability. Moreover, the cells showed synchronous beating behaviour from day 4 onwards. In addition, the initial concentration-dependent cytotoxicity studies demonstrated that doxorubicin at $156 \mathrm{nM}$ was still in a range that causes $<10 \%$ cell death, and its influence on beating rate was also less than $30 \%$. In contrast, doxorubicin concentrations higher than $156 \mathrm{nM}$ increased cytotoxicity and arrhythmic 
beating in hiPSC-CMs in a concentration-dependent manner (Supplementary Figs. S1 and S2).

\section{Repeated exposure to doxorubicin induced arrhythmic beats in cardiomyocytes}

Repeated doxorubicin exposure induced a decrease in normalized Cell Index values, which indicates a decrease in cell viability (Fig. 2a). During drug washout, especially in repeatedly exposed cells, a decrease in Cell Index values was observed but at a slow rate. Repeated doxorubicin exposure induced cytotoxicity with a loss of cells in the doxorubicin DOX-Day6 and DOX-Day6WO groups (Fig. 2b). Analysis of data on beating cardiomyocytes showed that repeated doxorubicin exposure increased the beating rate at day 4 (DOX-Day4), and the same effect was still observed after long-term drug washout (Fig. 2c), whereas repeated exposure at day 6 decreased the beating rate (data not shown). This may be due to the cytotoxic effect of doxorubicin on cardiomyocytes under these exposure conditions. Compared to controls, doxorubicin single exposure did not influence beating rates significantly during exposure and washout. Representative changes in beating activity were captured after doxorubicin exposure and washout (Fig. 2d). Arrhythmic beating activity was observed in DOX-Day6 and DOX-Day6WO cells. Unlike DOX-Day2 cells, repeated exposure caused a significant decrease in the beating amplitude during exposure and washout (Fig. 2e). This may be explained by the decreased number of cells contributing to the total contraction.

\section{Genome-wide analysis of cells with and without doxorubicin washout identifies clusters of reversibly and irreversibly altered genes}

To obtain an overview of genome-wide gene expression alterations induced by the different exposure schedules to doxorubicin, principal component analysis (PCA) was performed based on the significantly altered transcripts (FDR $p$ value $<0.05$; fold change $\geq 2.0$ ) (Fig. $3 \mathrm{a}$ ). The first component PC1 described $64 \%$ of the variance of the data and showed clear separation between controls and doxorubicinexposed and washout samples. The second component (PC2) described $10 \%$ of the variance within the data and represented the distance between samples with and without washout. During the drug washout period, DOX-Day2WO returned almost to control levels, whereas DOX-Day6WO showed a much smaller degree of recovery. Genes with at least twofold changes in expression values were identified and analysed by k-means clustering (Fig. 3b). This technique identified clusters of genes with different response patterns to doxorubicin and also distinct reversibility after washout of the test compound. Cluster 1 genes showed up-regulation after doxorubicin exposure, but returned to basal levels after drug washout (Fig. 3b). The strongest overrepresented GO terms in this cluster represented genes involved in nucleosome organization and DNA-protein complex assembly (Table 1). Cluster 2 genes were up-regulated by doxorubicin exposure and interestingly remained up-regulated even after washout of the test compound (Fig. 3b). In this cluster, endoplasmic reticulum genes and the endoplasmic reticulum-nuclear signalling pathway were overrepresented. Genes in cluster 3 were down-regulated by doxorubicin and mostly recovered after the washout (Fig. 3b). Interestingly, the strongest overrepresented GO groups in this cluster were associated with the sarcomere, myofibrils, contractile fibre part and regulation of heart contraction. Therefore, cluster 3 contains genes that were clearly associated with normal heart function and therefore should be of high interest as biomarkers of cardiotoxicity. Expression of cluster 4 genes was up-regulated upon doxorubicin exposure and decreased again after washout of the test compound, although not completely to control levels. Cluster 4 genes represented a cell stress response, with the p53 signalling pathway and apoptosis GO terms being overrepresented. Cluster 5 was a relatively small group of genes that were down-regulated after doxorubicin exposure and included overrepresented endogenous metabolism and extracellular matrix genes. Cluster 6 genes were down-regulated by doxorubicin and remained repressed even after washout. A strong overrepresentation of mitosis-associated genes occurred in this cluster. The genes of the individual clusters are listed in Supplemental Table 1, and all significant GO groups of the clusters are provided in Supplemental Table 2.

\section{Doxorubicin exposure down-regulates genes of cardiac function and up-regulates stress-associated genes}

Doxorubicin exposure led to 2195 differentially expressed probe sets (FDR $p$ value $<0.05$; fold change $\geq 2$ ), which were used for further analysis. Venn diagram analysis of deregulated genes between DOX-Day2 and DOX-Day6 displayed a list of 462 mutually down- and 376 mutually upregulated genes (Fig. 3c, d). These commonly down- and up-regulated genes were used separately for GO enrichment analysis using the DAVID functional enrichment tool. This analysis led to the identification of early doxorubicinresponsive cardiac processes, pathways and general toxic responses. The GO analysis showed that down-regulated genes were mainly enriched in GOs such as muscle contraction, sarcomere, cytoskeleton and 6 KEGG pathways (Table 2), whereas up-regulated GOs were mainly enriched in cell death, anti-apoptosis, DNA damage stimulus, oxidative stress responses and the KEGG pathways such as the p53 signalling pathway and apoptosis (Table 3 ). 
$\mathbf{A}$

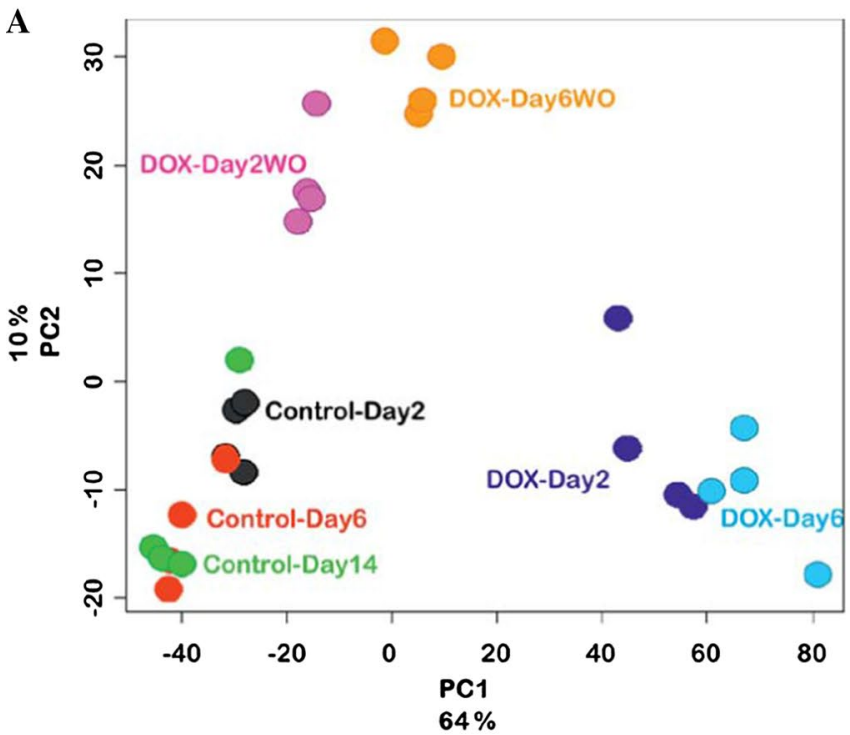

$\mathbf{C}$

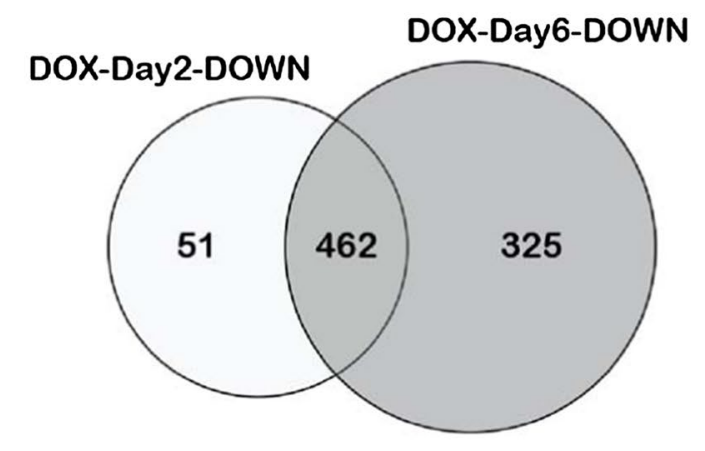

$\mathbf{E}$

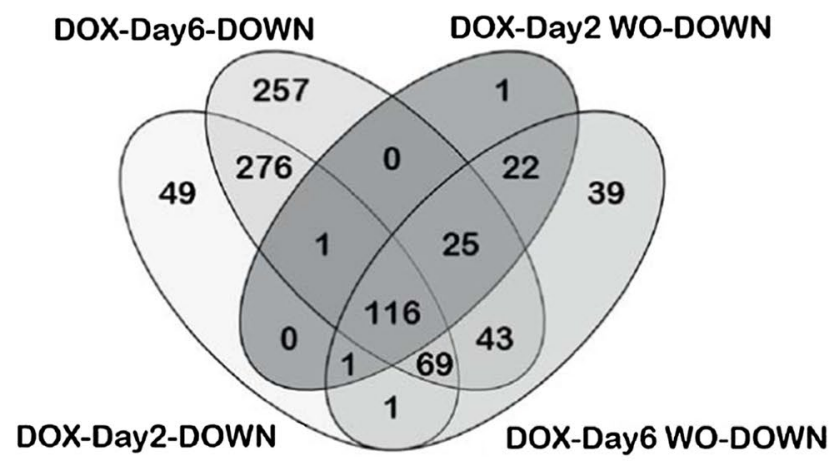

Fig. 3 Doxorubicin-induced differential gene regulation in cardiomyocytes. a 2D Principal component analysis (PCA) showed that doxorubicin exposure induces changes in gene expression depending on the exposure period. Each of the four replicates obtained from independent experiments is shown in single-coloured solid spheres. b k-means clustering analysis of 2195 transcripts differentially expressed between day 2, 6 and 14. Differentially expressed

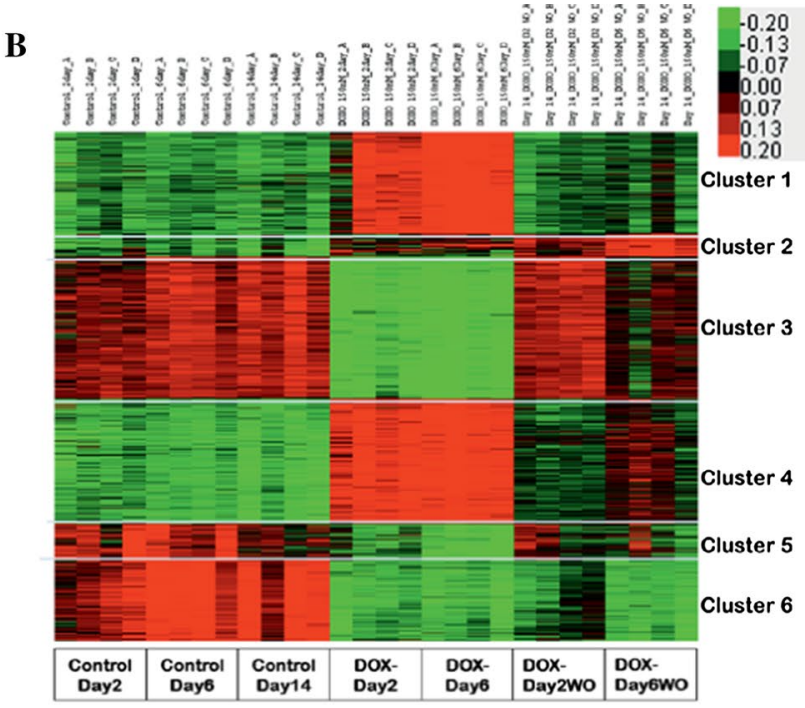

D

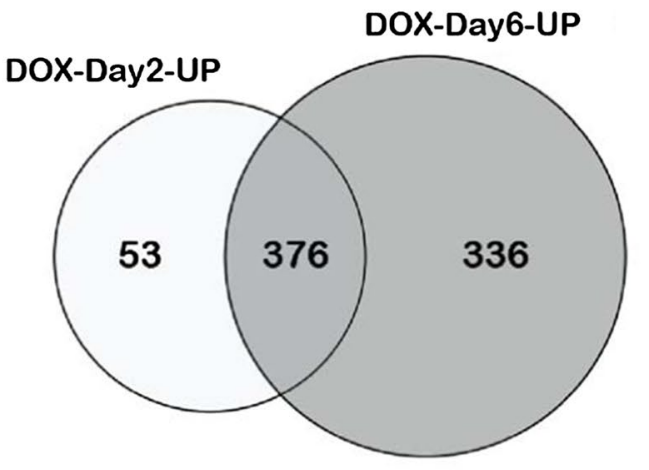

$\mathbf{F}$

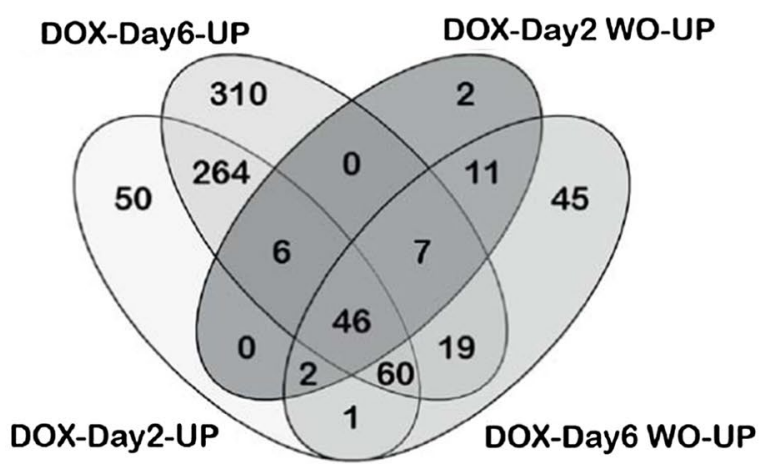

transcripts were grouped into six clusters based on their expression pattern upon doxorubicin exposure and washout $(\mathbf{a}, \mathbf{b}$ FDR $p$ value $<0.05$; fold change $\geq 2.0$ ). $\mathbf{c}, \mathbf{d}$ Venn diagrams illustrating overlapping down- and up-regulated genes between DOX-Day2 and DOX-Day6 groups. e, f Venn diagrams representing long-term down- and upregulated genes amongst all four experimental groups-DOX-Day2, DOX-Day6, DOX-Day2WO and DOX-Day6WO 
Table 1 Overrepresented GO categories and pathways of k-means cluster genes

\begin{tabular}{|c|c|c|}
\hline Term & Gene count & $p$ value \\
\hline \multicolumn{3}{|l|}{ Cluster 1} \\
\hline GO:0000786—nucleosome & 12 & $3.78 \mathrm{E}-09$ \\
\hline GO:0006334—nucleosome assembly & 13 & $7.54 \mathrm{E}-09$ \\
\hline $\begin{array}{l}\text { GO:0065004-protein-DNA complex } \\
\text { assembly }\end{array}$ & 13 & $1.91 \mathrm{E}-08$ \\
\hline \multicolumn{3}{|l|}{ Cluster 2} \\
\hline GO:0005783_endoplasmic reticulum & 14 & $8.80 \mathrm{E}-05$ \\
\hline $\begin{array}{l}\text { GO:0006984—ER-nuclear signalling } \\
\text { pathway }\end{array}$ & 4 & $2.76 \mathrm{E}-04$ \\
\hline GO:0005509—calcium ion binding & 12 & $4.54 \mathrm{E}-04$ \\
\hline \multicolumn{3}{|l|}{ Cluster 3} \\
\hline GO:0030017—sarcomere & 17 & $2.04 \mathrm{E}-09$ \\
\hline GO:0030016-myofibril & 17 & $1.31 \mathrm{E}-08$ \\
\hline GO:0044449—contractile fibre part & 17 & $1.70 \mathrm{E}-08$ \\
\hline $\begin{array}{l}\text { GO:0008016-regulation of heart contrac- } \\
\text { tion }\end{array}$ & 14 & $3.25 \mathrm{E}-08$ \\
\hline \multicolumn{3}{|l|}{ Cluster 4} \\
\hline hsa04115:p53 signalling pathway & 16 & $9.09 \mathrm{E}-11$ \\
\hline $\begin{array}{l}\text { GO:0043067—regulation of programmed } \\
\text { cell death }\end{array}$ & 45 & $1.80 \mathrm{E}-08$ \\
\hline GO:0042981-regulation of apoptosis & 44 & $3.88 \mathrm{E}-08$ \\
\hline \multicolumn{3}{|l|}{ Cluster 5} \\
\hline $\begin{array}{l}\text { GO:0019752 - carboxylic acid metabolic } \\
\text { process }\end{array}$ & 18 & $1.04 \mathrm{E}-06$ \\
\hline $\begin{array}{l}\text { GO:0006520—cellular amino acid meta- } \\
\text { bolic process }\end{array}$ & 11 & $9.33 \mathrm{E}-06$ \\
\hline GO:0005583—fibrillar collagen & 4 & $6.40 \mathrm{E}-05$ \\
\hline \multicolumn{3}{|l|}{ Cluster 6} \\
\hline GO:0000279-M phase & 78 & $6.83 \mathrm{E}-66$ \\
\hline GO:0007067—mitosis & 61 & $5.46 \mathrm{E}-55$ \\
\hline $\begin{array}{l}\text { GO:0000087-M phase of mitotic cell } \\
\text { cycle }\end{array}$ & 61 & $1.82 \mathrm{E}-54$ \\
\hline
\end{tabular}

Moreover, Venn diagram analysis of deregulated genes in DOX-Day2, DOX-Day6, DOX-Day2WO and DOXDay6WO revealed 116 down- and 46 up-regulated genes, which did not recover during the washout period and showed long-term deregulation (Fig. 3e, f). These 46 upregulated genes had enriched GOs such as apoptosis, DNA damage, stress-responsive processes and the KEGG p53 signalling pathway (Table 4), whereas down-regulated genes did not show significant enrichment in cardiac- and toxicity-related biological processes as well as in the KEGG pathways. This analysis suggests that doxorubicin negatively affected the expression of many cardiac genes, which are essential for an intact function of cardiomyocytes.

\section{Validation of deregulated genes by real-time PCR and follow-up by further cardiotoxic compounds}

From the above-described transcriptomic data and GO results, 84 significantly early and/or long-term deregulated genes were selected to validate their mRNA levels using real-time PCR. Most of them belong to cluster 3 (Fig. 3b), which was considered as particularly relevant because it represents contractile fibres and myofibril-associated genes. This gene panel includes 50 down- and 34 up-regulated doxorubicin-induced genes with at least a twofold change. Selected genes were mostly cardiac specific with involvement in cardiac contraction (preferably sarcomeric genes), ion homeostasis, cardiac physiology and pathophysiology, whereas another set of genes were associated with apoptosis, DNA damage and stress responses. Out of 84 genes, 63 genes were consistently deregulated upon doxorubicin single and repeated exposure (except $L I F$ and $C A L M 1$, which were deregulated upon repeated exposure) and showed recovery during the washout period. Another 19 genes did not show full recovery during washout. Along with doxorubicin transcriptomic data validation, differential regulation of these 84 genes was also investigated in hiPSC-CMs incubated with daunorubicin $(10 \mathrm{nM})$ and mitoxantrone $(3 \mathrm{nM})$ using real-time PCR. The daunorubicin and mitoxantrone test concentrations were determined using dose-dependent studies in hiPSC-CMs after $48 \mathrm{~h}$ of drug exposure (Supplementary Fig. S1). The selected test concentrations of daunorubicin and mitoxantrone did not induce cytotoxicity by more than $10 \%$ and also did not significantly influence beating rate or beating activity compared to controls (Supplementary Fig. S2-S4). Real-time PCR analysis revealed the deregulation of 65 genes in the doxorubicin group and confirmed the transcriptomics results by $77.4 \%$. The daunorubicin and mitoxantrone groups showed the deregulation of 41 genes in each group. Venn diagram analysis of the doxorubicin, daunorubicin and mitoxantrone groups displayed 35 commonly influenced genes: 27 down- and 8 up-regulated genes (Fig. 4a, b; Table 5).

\section{Doxorubicin-induced sarcomeric deterioration}

Our results showed that doxorubicin single exposures induced the down-regulation of sarcomeric genes. To investigate the effect of doxorubicin single and repeated exposures on proteins relevant for sarcomere structure, cardiac troponin $\mathrm{T}$ and sarcomeric alpha actinin in cardiomyocytes were studied by immunohistochemistry. Unlike doxorubicin single exposures, repeated exposures decreased the expression of both sarcomeric proteins and resulted in an 
Table 2 Significantly enriched GO categories and pathways by commonly down-regulated genes between DOX-Day2 and DOX-Day6

\begin{tabular}{|c|c|c|c|}
\hline Components & Gene count & $p$ value & Representative genes \\
\hline \multicolumn{4}{|l|}{ GO term } \\
\hline GO:0006936-muscle contraction & 23 & $3.4 \mathrm{E}-11$ & $\begin{array}{l}\text { SLC8A1, TCAP, ACTA1, MYL3, PGAM2, MYH7, MYH6, } \\
\text { TNNI3, GJA5, EDNRA, DES, TNNT1, MYOM2, ARG2, RYR2, } \\
\text { ASPH, KCNH2, SCN5A, KCNQ1, CASQ2, HRC, SGCA, MB }\end{array}$ \\
\hline GO:0005856—cytoskeleton & 74 & $1.9 \mathrm{E}-10$ & $\begin{array}{l}\text { KIF23, PRC1, TTK, AURKA, AURKB, GTSE1, KIF2C, FRMD5, } \\
\text { DES, ANK2, LMOD2, MYC, TOP2A, LMOD3, TUBA1B, } \\
\text { ASPM, KIF14, CDC6, CDK1, KIF11, ACTA1, KIF15, TPX2, } \\
\text { LDB3, NUSAP1, MYH7, MYH6, MCM3, TNNT1 }\end{array}$ \\
\hline GO:0030017—sarcomere & 14 & $8.5 \mathrm{E}-07$ & $\begin{array}{l}\text { MYL2, ACTA1, TCAP, MYL3, LDB3, FHL2, MYH7, MYH6, } \\
\text { TNNI3, DES, TNNT1, ANK2, DMD, RYR2 }\end{array}$ \\
\hline GO:0003013—circulatory system process & 13 & 0.00262 & $\begin{array}{l}\text { MYL2, CORIN, TCAP, MYL3, MYH6, NPR3, ATP1A2, TNNI3, } \\
\text { EDNRA, RYR2, KCNH2, SCN5A, KCNQ1 }\end{array}$ \\
\hline GO:0016529—sarcoplasmic reticulum & 5 & 0.01542 & $P Y G M, S R L, R Y R 2, C A S Q 2, H R C$ \\
\hline \multicolumn{4}{|l|}{ KEGG pathways } \\
\hline hsa04260:Cardiac muscle contraction & 11 & $1.98 \mathrm{E}-05$ & $\begin{array}{l}\text { SLC8A1, MYL2, MYL3, ATP1B4, COX6A2, RYR2, MYH7, } \\
\text { ATP1A2, MYH6, TNNI3, CACNA2D2 }\end{array}$ \\
\hline hsa05410:Hypertrophic cardiomyopathy (HCM) & 11 & $4.24 \mathrm{E}-05$ & $\begin{array}{l}\text { SLC8A1, DES, MYL2, MYL3, DMD, RYR2, MYH7, MYH6, } \\
\text { TNNI3, CACNA2D2, SGCA }\end{array}$ \\
\hline hsa05414:Dilated cardiomyopathy & 11 & $8.42 \mathrm{E}-05$ & $\begin{array}{l}\text { SLC8A1, DES, MYL2, MYL3, DMD, RYR2, MYH7, MYH6, } \\
\text { TNNI3, CACNA2D2, SGCA }\end{array}$ \\
\hline hsa00240:Pyrimidine metabolism & 8 & 0.009192 & $\begin{array}{l}\text { PRIM1, NME4, NME2, NME3, NME1-NME2, POLE2, RRM2, } \\
\text { POLA1, TK1 }\end{array}$ \\
\hline $\begin{array}{l}\text { hsa05412:Arrhythmogenic right ventricular cardio- } \\
\text { myopathy (ARVC) }\end{array}$ & 7 & 0.011314 & SLC8A1, DES, DMD, RYR2, CACNA2D2, SGCA, CTNNA3 \\
\hline hsa00230:Purine metabolism & 10 & 0.013765 & $\begin{array}{l}\text { PRIM1, NME4, ADSSL1, NME2, NME3, NME1-NME2, } \\
\text { POLE2, PDE1C, RRM2, POLA1, PAICS }\end{array}$ \\
\hline
\end{tabular}

irregular structure of the troponin and actinin filaments as compared to untreated cardiomyocytes (Fig. 5).

\section{Discussion}

For reliable evaluation of cardiotoxicity, human relevant models are urgently required. Current preclinical cardiac safety studies have mainly relied on cardiac ion channels, especially the human ether-a-go-go (hERG) channel, as well as in vivo tests. In the present study, we have established an in vitro cardiotoxicity methodology for the monitoring of early as well as chronic cardiotoxicity events at the cellular, functional and genomic level.

Doxorubicin is an established anti-cancer drug with well-known cardiac injury side effects. Its cumulative dosedependent cardiotoxicity (Appel et al. 2007; Menna et al. 2012) leads to congestive heart failure (Haq et al. 1985; Ibrahim et al. 1999). Doxorubicin has a tendency to disturb cardiac rhythm and in some cases can cause life-threatening arrhythmia or even sudden death (Lacasse and Bolduc 1992). The doxorubicin-induced disturbances in cardiac function can be detected within a few hours or within
24-48 h following doxorubicin administration by electrocardiography in human and animal hearts (Dindogru et al. 1978; Friess et al. 1985; Kehoe et al. 1978).

Our findings demonstrate that, unlike single exposure, repeated doxorubicin exposure caused arrhythmic beating on day 4 and induced substantial cytotoxicity accompanied with decreased beating amplitude on day 6. Doxorubicininduced arrhythmic beating indicates disturbed cardiac function, while the decreased amplitude reflects reduced contractile force. Our results are in agreement with findings demonstrating that chronic doxorubicin administration reduces contractile function in rabbit hearts (Boucek et al. 1997).

The GO and KEGG pathway analysis of our transcriptomic studies showed that doxorubicin exposure preferentially suppressed the expression of genes involved in cardiac contraction and pathways related to cardiomyopathies. In addition, doxorubicin exposure also deregulated genes with enriched biological processes such as apoptosis, DNA damage and the oxidative stress response. These observations show that in addition to a general stress response, genes involved in sarcomeric and cardiac muscle contraction are more responsive to doxorubicin exposure. Cardiomyocyte sarcomeres are highly organized structures of 
Table 3 Significantly enriched GO categories and pathways by commonly up-regulated genes between DOX-Day2 and DOX-Day6

\begin{tabular}{|c|c|c|c|}
\hline Components & Gene count & $p$ value & Representative genes \\
\hline \multicolumn{4}{|l|}{ GO terms } \\
\hline $\begin{array}{l}\text { GO:0006333—chromatin assembly or } \\
\text { disassembly }\end{array}$ & 14 & $2.9 \mathrm{E}-07$ & $\begin{array}{l}\text { HIST1H2AB, HIST2H2AA3, HIST2H2AA4, HIST4H4, HIST1H4L, } \\
\text { HIST1H4 K, HIST1H2AG, HIST1H2AD, HIST1H2AE, HIST2H4A, } \\
\text { HIST2H4B, H2BFS, HIST1H4A, HIST1H2BK, HIST1H4B, } \\
\text { HIST1H2BI, HIST1H4E, HIST1H4F }\end{array}$ \\
\hline $\begin{array}{l}\text { GO:0006974—response to DNA damage } \\
\text { stimulus }\end{array}$ & 19 & $8.6 \mathrm{E}-05$ & $\begin{array}{l}\text { XRCC4, RAD51C, POLH, ZMAT3, RPS27L, RRM2B, SESN1, RNF8, } \\
\text { TRIAP1, CDKN1A, CASP3, XPC, BTG2, BAX, UBR5, AEN, DDB2, } \\
\text { PCNA, GADD45A }\end{array}$ \\
\hline GO:0033554—cellular response to stress & 24 & $1.2 \mathrm{E}-04$ & $\begin{array}{l}\text { GADD45A, XRCC4, RAD51C, POLH, ZMAT3, RPS27L, RRM2B, } \\
\text { SESN1, RNF8, TRIAP1, DHRS2, GPX1, CASP3, CDKN1A, XPC, } \\
\text { BTG2, AEN, UBR5, BAX }\end{array}$ \\
\hline GO:0008219—cell death & 26 & $6.9 \mathrm{E}-04$ & $\begin{array}{l}\text { ZMAT3, GADD45A, BAX, KIT, STK17A, TP53INP1, PMAIP1, APLP1, } \\
\text { GPX1, TRIAP1, CASP3, TNFRSF11B, TMEM173, AEN, FAS, TRAF4, } \\
\text { PHLDA1, RNF144B, GAS1, NTN1, TNFRSF10A, TNFRSF10C, } \\
\text { TNFRSF10B, TNFRSF10D, }\end{array}$ \\
\hline GO:0006979—response to oxidative stress & 9 & 0.00772 & EGFR, GPX1, DHRS2, SDC1, RRM2B, NQO1, ETV5, ADA, OXR1 \\
\hline $\begin{array}{l}\text { GO:0050727-regulation of inflammatory } \\
\text { response }\end{array}$ & 6 & 0.01013 & $G P X 1, A 2 M, M A S P 1, A C E 2, I T G A 2, A D A$ \\
\hline GO:0005576—extracellular region & 44 & 0.02673 & $\begin{array}{l}\text { GDF15, ACE2,FGFR2, ADAMTS17, A2 M, SORD, IGFBPL1, MASP1, } \\
\text { NELL2, JAG1, KIT, LSR, ADA, APLP1, BDNF, TNFRSF11B, SER- } \\
\text { PINE2, COL27A1, FAS, NRG1, TFPI2, PCSK5, GFOD1, THBS4, } \\
\text { EGFR, TMEFF2, FLRT2, ICAM4 }\end{array}$ \\
\hline GO:0006916-anti-apoptosis & 9 & 0.02699 & $\begin{array}{l}\text { TRIAP1, GPX1, BDNF, TNFRSF10D, BAX, FAS, NRG1, ANXA4, } \\
\quad \text { GSTP1 }\end{array}$ \\
\hline \multicolumn{4}{|l|}{ KEGG pathways } \\
\hline hsa04115:p53 signalling pathway & 16 & $5.2 \mathrm{E}-12$ & $\begin{array}{l}\text { ZMAT3, RRM2B, PMAIP1, SESN2, SESN1, EI24, TP53I3, PPM1D, } \\
\text { CDKN1A, CASP3, TNFRSF1OB, BAX, DDB2, MDM2, FAS, } \\
\text { GADD45A }\end{array}$ \\
\hline hsa04210:Apoptosis & 9 & $4.6 \mathrm{E}-04$ & $\begin{array}{l}\text { TNFRSF10A, CASP3, TNFRSF10C, TNFRSF10B, TNFRSF10D, BAX, } \\
\text { ENDOD1, FAS, PRKX }\end{array}$ \\
\hline
\end{tabular}

Table 4 Long-term up-regulated genes enriched GO categories and pathways

\begin{tabular}{llll}
\hline Components & Gene count & $p$ value & Representative genes \\
\hline GO term & & & \\
GO:0006917—induction of apoptosis & 5 & 0.0030 & TNFRSF10A, CDKN1A, ZMAT3, RRM2B, FAS \\
GO:0033554—cellular response to stress & 6 & 0.0039 & XRCC4, CDKN1A, ZMAT3, RRM2B, NEFL, ETV5 \\
GO:0006974—-response to DNA damage stimulus & 4 & 0.0338 & XRCC4, CDKN1A, ZMAT3, RRM2B \\
KEGG pathways & 5 & & \\
hsa04115:p53 signalling pathway & 5 & $4.7 \mathrm{E}-05$ & CDKN1A, ZMAT3, MDM2, RRM2B, FAS \\
\hline
\end{tabular}

myofilaments and are involved in mechanical cardiac contraction. Our transcriptomic data showed significant downregulation of sarcomere genes in DOX-Day2 and DOXDay6 cells. Similar findings have also been reported in rat cardiomyocytes, in which chronic doxorubicin exposure induces significant degeneration of sarcomeres (Sussman et al. 1997). Our immunocytochemical analysis showed that compared to control and DOX-Day 2 cells, repeated doxorubicin exposure resulted in decreased expression of cardiac troponin $\mathrm{T}$ and sarcomeric $\alpha$-actinin proteins in
DOX-Day6 cells, and this expression remained at lower levels even after doxorubicin washout in DOX-Day6WO. In addition, disorganization of myofibrillar structures in the DOX-Day6 cardiomyocytes has been observed. Doxorubicin-induced myofibrillar disarray has also been reported in rat ventricular cardiomyocytes (Sussman et al. 1997; Sawyer et al. 2002).

Regulation of ion homeostasis is one of the essential functional elements during cardiac contraction. Intracellular calcium $\left(\mathrm{Ca}^{2+}\right)$ is the central regulator of cardiac 
A

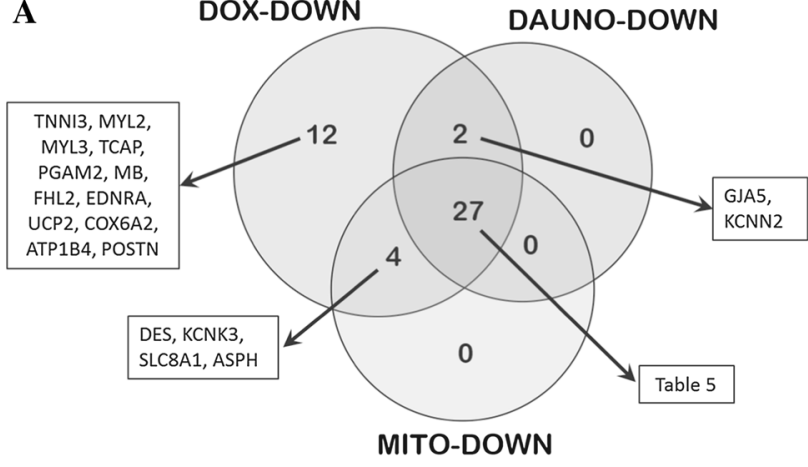

B

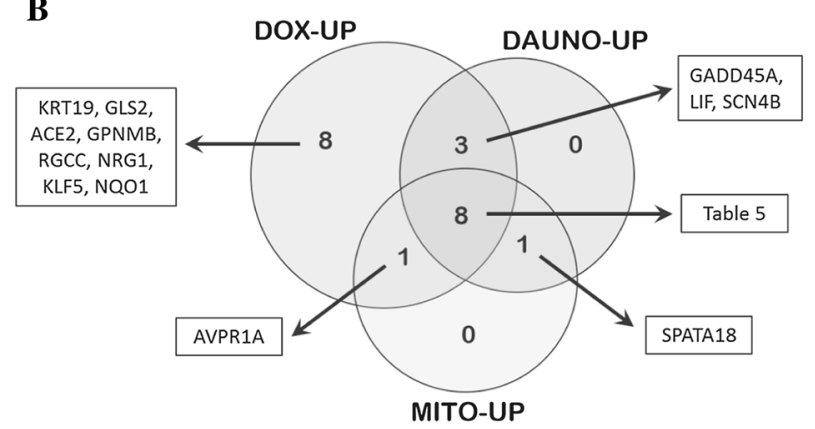

Fig. 4 Venn diagrams representing number of common and drugspecific deregulated genes following $48 \mathrm{~h}$ exposure to anthracyclines in hiPSC-CMs. a Commonly down-regulated 27 genes and b commonly up-regulated 8 genes among doxorubicin (DOX), daunorubicin (DAUNO) and mitoxantrone (MITO) groups

contraction, and its homeostasis is tightly regulated by $\mathrm{Ca}^{2+}$ ion channels, $\mathrm{Ca}^{+2}$ receptors and $\mathrm{Ca}^{+2}$ binding proteins. Our data showed down-regulation of $\mathrm{Ca}^{2+}$-transporting genes such as RYR2, SLC8A1, CACNA1G, CACNA2D2 and ITPRI in doxorubicin-exposed hiPSC-CMs. Differential regulation of two calcium release channels (RYR2 and ITPR1) has been reported during end stage heart failure (Go et al. 1995). Chronic rabbit heart studies have shown alterations in $\mathrm{Ca}^{2+}$ release causing abnormalities of contractions and relaxation in doxorubicin-induced cardiomyopathy (Dodd et al. 1993). In addition, we found down-regulation of sodium $\left(\mathrm{Na}^{+}\right)$and potassium $\left(\mathrm{K}^{+}\right)$ion channel encoding genes, such as KCNQ1, KCNK3, KCNN2, KCNH2, SCN2B and $S C N 5 A$. Deregulated $\mathrm{Na}^{+}$and $\mathrm{K}^{+}$ion channels play an important role in cardiac arrhythmias and heart failure (Remme and Bezzina 2010; Nabauer and Kaab 1998). In summary, our results are in accordance with animal and clinical studies demonstrating that doxorubicin induces disturbances in cardiac calcium homeostasis as well as altered sodium and potassium ion channel activity. In the present study, doxorubicin exposure significantly deregulated ion homeostasis maintaining genes at the mRNA level accompanied with functional changes in the beating behaviour of hiPSC-CMs.
Mitochondrial dysfunction has been suggested to be involved in doxorubicin-induced cardiotoxicity. However, the exact mechanisms of the suppressive effects by doxorubicin on the mitochondrial electron transport chain, oxidative metabolism and ATP synthesis are not fully understood. As a crucial component of the mitochondrial electron transport chain, cytochrome $\mathrm{C}$ oxidase $(\mathrm{CCo})$ and uncoupling protein (UCP) activity influences mitochondrial function at the ATP level. In rat hearts, doxorubicin treatment reduced CCo subunit expression (Chandran et al. 2009) and also down-regulated Ucp 2 and $U c p 3$ expression (Bugger et al. 2011). Down-regulation of UCPs and CCo genes showed an inverse relationship with increased oxidative stress (Akhmedov et al. 2015; Bugger et al. 2011; Srinivasan and Avadhani 2012); CCo dysfunction also has a direct effect on cellular ATP levels. In agreement with these observations, our data also indicated a down-regulation of UCP2 and CCo (Cytochrome C Oxidase Subunit VIa Polypeptide 2) expression, whereas up-regulation was observed for oxidative stress-responsive genes such as NQO1, OXR, GCH1 and GPXI in doxorubicin-exposed hiPSC-CMs (supplementary Fig. S5). Similarly to our findings, the reduced activity of creatine kinase muscle (CKM) and myoglobin (MB) has been reported in human failing hearts (Braunlin et al. 1986; Nascimben et al. 1996; Obrien et al. 1992). Decreased levels of CKM impair the ATP delivery process to energy-consuming systems, and decreased levels of MB disturb oxygen diffusion and the mechanical functions of the cardiac muscle. In conclusion, the present results suggest that doxorubicin induces increased oxidative stress and impairs mitochondrial ATP synthesis and delivery in cardiomyocytes. Overall, these intracellular mechanisms contribute to the impaired cardiac function observed after doxorubicin treatment in cancer patients.

In accordance with our findings, the expression level of apoptosis genes including $B A X$ and $F A S$ has also been found to be up-regulated in human failing hearts (Latif et al. 2000; Sheppard et al. 2005). Increased expression of $B A X$ and $F A S$ may induce apoptosis and reduce the chances of myocardial recovery. Similarly to our results, increased expression levels of ACE2, NRG1, DUSP4 and LIF have also been found in human heart failure (Goulter et al. 2004; Yan and Morgan 2011; Communal et al. 2002; Eiken et al. 2001). KCNJ2 is also up-regulated in human dilated cardiomyopathy (Szuts et al. 2013). Notably, GDF15 and GPNMB (patent publication number-WO2012072752 A1) have been proposed as diagnostic biomarkers of heart failure (Wang et al. 2010; Kempf and Wollert 2009; Khan et al. 2009) and were also up-regulated in our model system. Therefore, the gene expression responses observed in our established in vitro system showed a high degree of similarity to those of the human heart in vivo. 
Table 5 Gene expression studies (fold regulation) by realtime PCR in hiPSC-CMs after $48 \mathrm{~h}$ exposure of doxorubicin $(156 \mathrm{nM})$, daunorubicin $(10 \mathrm{nM})$ and mitoxantrone $(3 \mathrm{nM})$

\begin{tabular}{|c|c|c|c|c|c|c|}
\hline \multirow[t]{2}{*}{ Gene symbol } & \multicolumn{3}{|c|}{ Fold regulation } & \multicolumn{3}{|l|}{$p$ value } \\
\hline & Doxorubicin & Daunorubicin & Mitoxantrone & Doxorubicin & Daunorubicin & Mitoxantrone \\
\hline ACTA1 & -211.2 & -5.0 & -11.7 & $7.5 \mathrm{E}-05$ & $9.7 \mathrm{E}-03$ & $4.6 \mathrm{E}-03$ \\
\hline TNNT1 & -31.1 & -2.7 & -2.7 & $3.4 \mathrm{E}-05$ & $6.8 \mathrm{E}-03$ & $7.3 \mathrm{E}-03$ \\
\hline$H R C$ & -467.6 & -38.1 & -48.1 & $8.2 \mathrm{E}-04$ & $5.2 \mathrm{E}-04$ & $2.9 \mathrm{E}-03$ \\
\hline MYOM2 & -50.0 & -9.7 & -22.1 & $6.2 \mathrm{E}-04$ & $2.1 \mathrm{E}-03$ & $9.8 \mathrm{E}-03$ \\
\hline МYH6 & -290.8 & -60.3 & -76.8 & $1.5 \mathrm{E}-04$ & $3.2 \mathrm{E}-04$ & $5.5 \mathrm{E}-04$ \\
\hline MYH7 & -2684.9 & -182.1 & -179.4 & $2.7 \mathrm{E}-05$ & $6.9 \mathrm{E}-05$ & $3.9 \mathrm{E}-04$ \\
\hline$A N K 2$ & -87.1 & -10.4 & -3.5 & $2.2 \mathrm{E}-03$ & $5.4 \mathrm{E}-03$ & $9.1 \mathrm{E}-02$ \\
\hline$L D B 3$ & -128.4 & -12.0 & -19.3 & $9.4 \mathrm{E}-05$ & $2.4 \mathrm{E}-04$ & $5.3 \mathrm{E}-04$ \\
\hline$D M D$ & -9.6 & -10.4 & -22.4 & $2.1 \mathrm{E}-03$ & $4.8 \mathrm{E}-04$ & $7.5 \mathrm{E}-04$ \\
\hline$N R A P$ & -21.8 & -19.4 & -22.8 & $9.5 \mathrm{E}-05$ & $2.3 \mathrm{E}-04$ & $1.5 \mathrm{E}-03$ \\
\hline ATP1A2 & -248.2 & -9.3 & -25.6 & $1.9 \mathrm{E}-02$ & $2.3 \mathrm{E}-03$ & $8.3 \mathrm{E}-03$ \\
\hline$K C N Q 1$ & -29.1 & -4.2 & -4.9 & $1.3 \mathrm{E}-04$ & $3.1 \mathrm{E}-03$ & $8.2 \mathrm{E}-03$ \\
\hline KCNH2 & -29.1 & -5.9 & -6.3 & $2.6 \mathrm{E}-04$ & $8.9 \mathrm{E}-03$ & $1.3 \mathrm{E}-02$ \\
\hline$S C N 2 B$ & -19.7 & -4.7 & -5.1 & $7.6 \mathrm{E}-04$ & $8.5 \mathrm{E}-03$ & $1.1 \mathrm{E}-02$ \\
\hline SCN5A & -119.9 & -37.6 & -28.2 & $3.1 \mathrm{E}-04$ & $1.9 \mathrm{E}-03$ & $1.8 \mathrm{E}-03$ \\
\hline CACNA2D2 & -52.4 & -68.3 & -59.4 & $8.1 \mathrm{E}-03$ & $5.0 \mathrm{E}-03$ & $4.2 \mathrm{E}-03$ \\
\hline$P Y G M$ & -457.1 & -8.2 & -11.8 & $1.4 \mathrm{E}-04$ & $4.4 \mathrm{E}-04$ & $4.8 \mathrm{E}-04$ \\
\hline$C K M$ & -71.1 & -2.5 & -1.9 & $6.1 \mathrm{E}-05$ & $2.9 \mathrm{E}-03$ & $3.1 \mathrm{E}-02$ \\
\hline MURC & -22.8 & -9.6 & -7.4 & $1.3 \mathrm{E}-03$ & $8.3 E-04$ & $1.0 \mathrm{E}-03$ \\
\hline$E R B B 3$ & -20.5 & -7.3 & -5.0 & $2.6 \mathrm{E}-04$ & $2.9 \mathrm{E}-03$ & $2.7 \mathrm{E}-03$ \\
\hline$J A K 2$ & -18.6 & -3.2 & -4.4 & $4.9 \mathrm{E}-04$ & $1.8 \mathrm{E}-02$ & $1.8 \mathrm{E}-03$ \\
\hline PPP1R3A & -15.2 & -3.5 & -7.9 & $5.0 \mathrm{E}-03$ & $1.9 \mathrm{E}-03$ & $1.0 \mathrm{E}-02$ \\
\hline$R Y R 2$ & -136.7 & -26.9 & -82.5 & $1.6 \mathrm{E}-03$ & $1.3 \mathrm{E}-04$ & $5.3 \mathrm{E}-03$ \\
\hline IRX4 & -21.4 & -5.6 & -6.2 & $2.4 \mathrm{E}-04$ & $7.5 \mathrm{E}-03$ & $3.4 \mathrm{E}-03$ \\
\hline CORIN & -68.8 & -5.9 & -15.9 & $5.9 \mathrm{E}-04$ & $3.6 \mathrm{E}-03$ & $2.9 \mathrm{E}-03$ \\
\hline CACNA1G & -75.5 & -62.0 & -42.4 & $6.5 \mathrm{E}-04$ & $2.1 \mathrm{E}-03$ & $1.7 \mathrm{E}-04$ \\
\hline PRDM16 & -35.3 & -28.5 & -35.8 & $1.3 \mathrm{E}-02$ & $6.2 \mathrm{E}-04$ & $9.8 \mathrm{E}-04$ \\
\hline$B A X$ & 7.72 & 3.91 & 2.93 & $2.9 \mathrm{E}-04$ & $3.7 \mathrm{E}-04$ & $5.5 \mathrm{E}-04$ \\
\hline ZMAT3 & 3.3 & 3.4 & 2.0 & $5.3 \mathrm{E}-03$ & $3.4 \mathrm{E}-03$ & $1.6 \mathrm{E}-02$ \\
\hline GDF15 & 8.8 & 2.6 & 6.9 & $5.2 \mathrm{E}-04$ & $1.5 \mathrm{E}-02$ & $8.7 \mathrm{E}-03$ \\
\hline$F A S$ & 18.3 & 7.3 & 5.7 & $3.1 \mathrm{E}-05$ & $3.6 \mathrm{E}-05$ & $4.2 \mathrm{E}-05$ \\
\hline$P R K X$ & 1.9 & 2.6 & 2.1 & $7.3 \mathrm{E}-02$ & $1.5 \mathrm{E}-02$ & $1.1 \mathrm{E}-02$ \\
\hline DUSP4 & 15.8 & 3.1 & 2.5 & $1.9 \mathrm{E}-03$ & $8.7 \mathrm{E}-03$ & $2.2 \mathrm{E}-02$ \\
\hline KCNJ2 & 18.7 & 2.3 & 2.8 & $1.3 \mathrm{E}-04$ & $1.8 \mathrm{E}-02$ & $6.4 \mathrm{E}-03$ \\
\hline$G P X 1$ & 15.8 & 2.4 & 2.6 & $1.6 \mathrm{E}-04$ & $7.3 \mathrm{E}-03$ & $2.6 \mathrm{E}-03$ \\
\hline
\end{tabular}

The numerical data represent the fold regulation values compared to controls. The $p$ value is calculated based on a Student's $t$ test of the Ct values $(n=3)$. $p$ value $\leq 0.05$ is considered significant
The Venn diagram analysis of differentially expressed genes in cells exposed to doxorubicin, daunorubicin and mitoxantrone exhibited an overlap of 27 down- and 8 upregulated genes. The 27 down-regulated genes are mainly involved in sarcomere structure and the regulation of ion homeostasis. Up-regulated genes mainly indicate a general stress response, and they included stress markers such as BAX, FAS, GPXI and ZMAT3. This observation may help to better understand cellular mechanisms underlying late apoptosis inducing cardiac cell loss many years after anthracycline treatment. Although GDF15 has been reported to represent a biomarker for heart failure, elevated levels have also been found in the cell systems of liver, lung and kidney injury (Hsiao et al. 2000; Zimmers et al. 2005). Thus, it can be interpreted as a marker which indicates cell injury in multiple tissues. The identified 35 genes in the overlap of all three anthracyclines represent an anthracycline-responsive gene consensus expression signature and could be applied as a predictive toxicity signature for potential cardiotoxicants that act 


\section{Cardiac Troponin T}
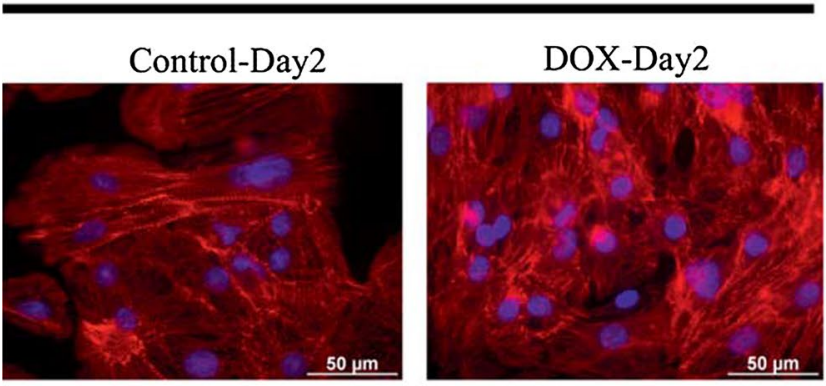

Control-Day6
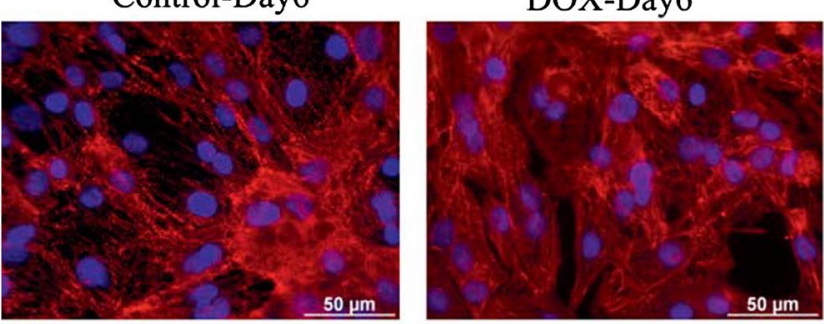

Control-Day14
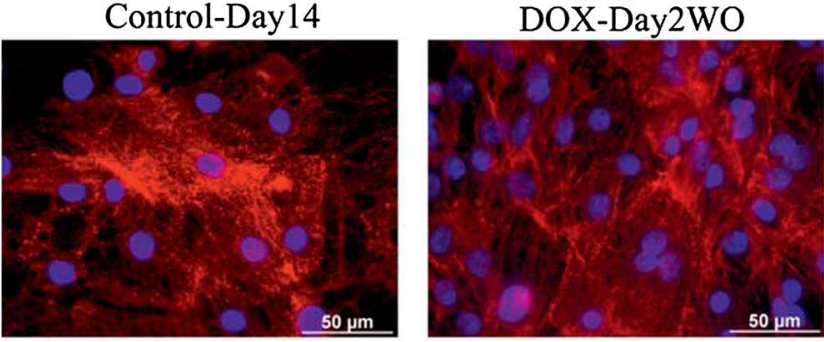

Control-Day 14

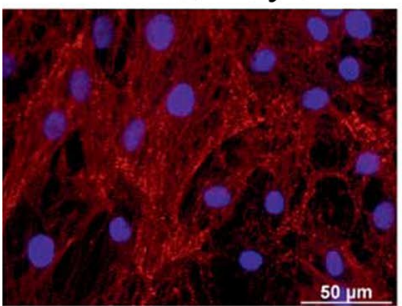

DOX-Day6WO

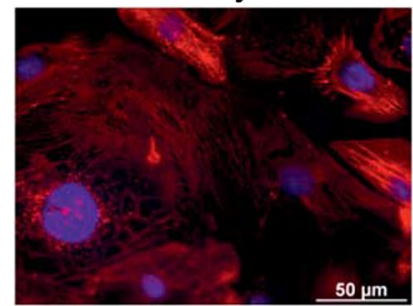

Fig. 5 Immunohistochemistry of cardiac troponin $T$ and sarcomeric cardiac $\alpha$-actinin proteins in control, doxorubicin-exposed and washout hiPSC-CMs. Red and green colours indicate cardiac troponin T and sarcomeric alpha actinin staining, respectively. Blue colour indi-

by similar mechanisms as doxorubicin, daunorubicin or mitoxantrone.

In the present study, a concentration of $156 \mathrm{nM}$ doxorubicin was chosen because in the hiPSC-CMs this concentration compromises the contractility without causing major cytotoxic effects. At doses of bolus administration of doxorubicin varying between 15 and $90 \mathrm{mg} / \mathrm{m}^{2}$, the initial maximal plasma concentrations in patients are approximately $5 \mu \mathrm{M}$ (Gewirtz 1999). After this initial peak, the plasma concentration of doxorubicin decreases rapidly, to
Sarcomeric Alpha Actinin
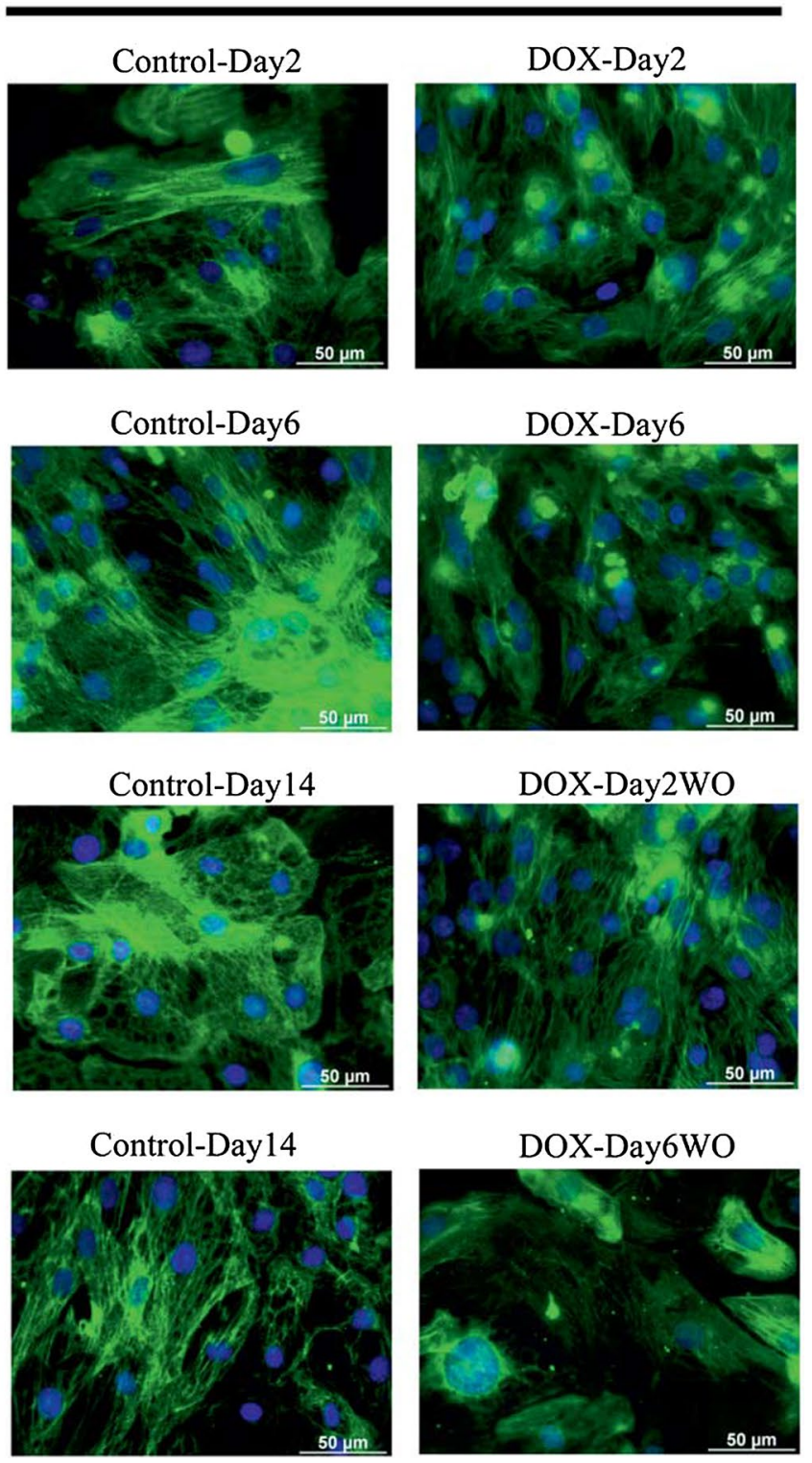

cates nuclear staining. Immunofluorescence results demonstrate a significant decrease in both protein expression levels in DOX-Day6 and DOX-Day6WO cells. Scale bar represents $50 \mu \mathrm{m}$ (colour figure online)

the range of 25-250 nM, within $1 \mathrm{~h}$. Similar plasma concentrations have also been reported in patients receiving continuous infusions of doxorubicin (Gewirtz 1999). In addition, after a $50 \mathrm{mg} / \mathrm{m}^{2}$ intravenous injection in adult acute myeloid leukaemia patients, a daunorubicin peak plasma concentration range from 120 to $560 \mathrm{nM}$ on day 1 and 8 to $610 \mathrm{nM}$ on day 3 has been observed (Lofgren et al. 2007). The mitoxantrone peak plasma concentrations have been reported to vary from 0.46 to $2.49 \mu \mathrm{M}$ after $1 \mathrm{~h}$ infusion of mitoxantrone $\left(12 \mathrm{mg} / \mathrm{m}^{2}\right)$ and then decrease 
rapidly to around $10 \mathrm{nM}$ within $5 \mathrm{~h}$ (Sundman-Engberg et al. 1993). Therefore, the concentration chosen in the present study is within the therapeutic range of anthracyclines therapy.

In summary, the results obtained by anthracyclines in hiPSC-CMs recapitulated the disturbed cardiac function observed in vivo and in clinical studies. Doxorubicininduced adverse effects on cardiac function can be detected much earlier at the genomic level before cytotoxicity and arrhythmia can be observed. The combined application of hiPSC-CMs, the xCELLigence RTCA Cardio system and transcriptomics resulted in the identification of an anthracycline consensus signature representing early biological processes that significantly contribute to better understanding of the cardiotoxic effects of compounds both at a cellular and molecular level. The present methodology can allow for first-line in vitro preclinical tests and reduce animal usage in drug safety studies and the costs of safety evaluation. Although it is very likely that the methodology possesses a low false negative rate for severely cardiotoxic compounds, however, whether this approach can avoid false negatives for mildly cardiotoxic compounds and false positives for non-cardiotoxic compounds should be demonstrated by screening of several non- and mild cardiotoxicants.

Acknowledgments This work was supported by the 'Detection of endpoints and biomarkers for repeated dose toxicity using in vitro systems' (DETECTIVE) Project (FP7 Health Programme, European Commission).

Open Access This article is distributed under the terms of the Creative Commons Attribution 4.0 International License (http://creativecommons.org/licenses/by/4.0/), which permits unrestricted use, distribution, and reproduction in any medium, provided you give appropriate credit to the original author(s) and the source, provide a link to the Creative Commons license, and indicate if changes were made.

\section{References}

Akhmedov AT, Rybin V, Marin-Garcia J (2015) Mitochondrial oxidative metabolism and uncoupling proteins in the failing heart. Heart Fail Rev 20:227-249

Anson BD, Kolaja KL, Kamp TJ (2011) Opportunities for use of human iPS cells in predictive toxicology. Clin Pharmacol Ther 89:754-758

Appel JM, Nielsen D, Zerahn B, Jensen BV, Skagen K (2007) Anthracycline-induced chronic cardiotoxicity and heart failure. Acta Oncol 46:576-580

Babuin L, Jaffe AS (2005) Troponin: the biomarker of choice for the detection of cardiac injury. CMAJ 173:1191-1202

Boucek RJ, Dodd DA, Atkinson JB, Oquist N, Olson RD (1997) Contractile failure in chronic doxorubicin-induced cardiomyopathy. $\mathrm{J}$ Mol Cell Cardiol 29:2631-2640

Braunlin EA, Wahler GM, Swayze CR, Lucas RV, Fox IJ (1986) Myoglobin facilitated oxygen diffusion maintains mechanical function of mammalian cardiac-muscle. Cardiovasc Res 20:627-636

Bugger H, Guzman C, Zechner C, Palmeri M, Russell KS, Russell RR (2011) Uncoupling protein downregulation in doxorubicininduced heart failure improves mitochondrial coupling but increases reactive oxygen species generation. Cancer Chemother Pharmacol 67:1381-1388

Caspi O, Itzhaki I, Kehat I, Gepstein A, Arbel G, Huber I, Satin J, Gepstein L (2009) In vitro electrophysiological drug testing using human embryonic stem cell derived cardiomyocytes. Stem Cells Dev 18:161-172

Chandran K, Aggarwal D, Migrino RQ, Joseph J, McAllister D, Konorev EA, Antholine WE, Zielonka J, Srinivasan S, Avadhani NG, Kalyanaraman B (2009) Doxorubicin inactivates myocardial cytochrome c oxidase in rats: cardioprotection by Mito-Q. Biophys J 96:1388-1398

Communal C, Colucci WS, Remondino A, Sawyer DB, Port JD, Wichman SE, Bristow MR, Singh K (2002) Reciprocal modulation of mitogen-activated protein kinases and mitogen-activated protein kinase phosphatase 1 and 2 in failing human myocardium. J Card Fail 8:86-92

Dennis G, Sherman BT, Hosack DA, Yang J, Gao W, Lane HC, Lempicki RA (2003) DAVID: database for annotation, visualization, and integrated discovery. Genome Biol 4:R60

Dindogru A, Barcos M, Henderson ES, Wallace HJ (1978) Electrocardiographic changes following adriamycin treatment. Med Pediatr Oncol 5:65-71

Dodd DA, Atkinson JB, Olson RD, Buck S, Cusack BJ, Fleischer S, Boucek RJ (1993) Doxorubicin cardiomyopathy is associated with a decrease in calcium release channel of the sarcoplasmicreticulum in a chronic rabbit model. J Clin Invest 91:1697-1705

Eiken HG, Oie E, Damas JK, Yndestad A, Bjerkeli V, Aass H, Simonsen S, Geiran OR, Tonnessen T, Christensen G, Froland SS, Gullestad L, Attramadal H, Aukrust P (2001) Myocardial gene expression of leukaemia inhibitory factor, interleukin-6 and glycoprotein 130 in end-stage human heart failure. Eur J Clin Invest 31:389-397

Eisen MB, Spellman PT, Brown PO, Botstein D (1999) Cluster analysis and display of genome-wide expression patterns (vol 95, pg 14863, 1998). Proc Natl Acad Sci USA 96:10943

Friess GG, Boyd JF, Geer MR, Garcia JC (1985) Effects of 1st-dose doxorubicin on cardiac-rhythm as evaluated by continuous 24-hour monitoring. Cancer 56:2762-2764

Gautier L, Cope L, Bolstad BM, Irizarry RA (2004) affy—analysis of Affymetrix GeneChip data at the probe level. Bioinformatics 20:307-315

Gewirtz D (1999) A critical evaluation of the mechanisms of action proposed for the antitumor effects of the anthracycline antibiotics adriamycin and daunorubicin. Biochem Pharmacol 57:727-741

Go LO, Moschella MC, Watras J, Handa KK, Fyfe BS, Marks AR (1995) Differential regulation of 2 types of intracellular calciumrelease channels during end-stage heart-failure. J Clin Invest 95:888-894

Goulter AB, Goddard MJ, Allen JC, Clark KL (2004) ACE2 gene expression is up-regulated in the human failing heart. BMC Med 2:19

Haq MM, Legha SS, Choksi J, Hortobagyi GN, Benjamin RS, Ewer M, Ali M (1985) Doxorubicin-induced congestive heart-failure in adults. Cancer 56:1361-1365

He JQ, Ma Y, Lee Y, Thomson JA, Kamp TJ (2003) Human embryonic stem cells develop into multiple types of cardiac myocytes - action potential characterization. Circ Res 93:32-39

Hsiao EC, Koniaris LG, Zimmers-Koniaris T, Sebald SM, Huynh TV, Lee SJ (2000) Characterization of growth-differentiation factor 15 , a transforming growth factor beta superfamily member induced following liver injury. Mol Cell Biol 20:3742-3751 
Ibrahim NK, Hortobagyi GN, Ewer M, Ali MK, Asmar L, Theriault RL, Fraschini G, Frye DK, Buzdar AU (1999) Doxorubicininduced congestive heart failure in elderly patients with metastatic breast cancer, with long-term follow-up: the M.D. Anderson experience. Cancer Chemother Pharmacol 43:471-478

Kehoe R, Singer DH, Trapani A, Billingham M, Levandowski R, Elson J (1978) Adriamycin-induced cardiac dysrhythmias in an experimental dog model. Cancer Treat Rep 62:963-978

Kempf T, Wollert KC (2009) Growth differentiation factor-15: a new biomarker in cardiovascular disease. Herz 34:594-599

Khan SQ, Ng K, Dhillon O, Kelly D, Quinn P, Squire IB, Davies JE, $\mathrm{Ng}$ LL (2009) Growth differentiation factor-15 as a prognostic marker in patients with acute myocardial infarction. Eur Heart J 30:1057-1065

Lacasse Y, Bolduc P (1992) Sudden-death in leukemic patients treated with doxorubicin. Can J Cardiol 8:53-56

Latif N, Khan MA, Birks E, O'Farrell A, Westbrook J, Dunn MJ, Yacoub MH (2000) Upregulation of the Bcl-2 family of proteins in end stage heart failure. J Am Coll Cardiol 35:1769-1777

Lofgren C, Lehmann S, Jonsson-Videsater K, Mollgard L, Linder O, Tidefelt U, Hassan M, Paul C (2007) Higher plasma but not intracellular concentrations after infusion with liposomal daunorubicin compared with conventional daunorubicin in adult acute myeloid leukemia. Ther Drug Monit 29:626-631

Menna P, Paz OG, Chello M, Covino E, Salvatorelli E, Minotti G (2012) Anthracycline cardiotoxicity. Expert Opin Drug Saf 11(Suppl 1):S21-S36

Minotti G, Menna P, Salvatorelli E, Cairo G, Gianni L (2004) Anthracyclines: molecular advances and pharmacologic developments in antitumor activity and cardiotoxicity. Pharmacol Rev $56: 185-229$

Nabauer M, Kaab S (1998) Potassium channel down-regulation in heart failure. Cardiovasc Res 37:324-334

Nascimben L, Ingwall JS, Pauletto P, Friedrich J, Gwathmey JK, Saks V, Pessina AC, Allen PD (1996) Creatine kinase system in failing and nonfailing human myocardium. Circulation 94:1894-1901

O'Brien PJ (2008) Cardiac troponin is the most effective translational safety biomarker for myocardial injury in cardiotoxicity. Toxicology 245:206-218

Obrien PJ, Ogrady M, Mccutcheon LJ, Shen H, Nowack L, Horne RD, Mirsalimi SM, Julian RJ, Grima EA, Moe GW, Armstrong PW (1992) Myocardial myoglobin deficiency in various animal-models of congestive-heart-failure. J Mol Cell Cardiol 24:721-730

Paul F, Dorr J, Wurfel J, Vogel HP, Zipp F (2007) Early mitoxantroneinduced cardiotoxicity in secondary progressive multiple sclerosis. J Neurol Neurosurg Psychiatry 78:198-200

Remme CA, Bezzina CR (2010) Sodium channel (dys)function and cardiac arrhythmias. Cardiovasc Ther 28:287-294

Reppel M, Pillekamp F, Brockmeier K, Matzkies M, Bekcioglu A, Lipke T, Nguemo F, Bonnemeier H, Hescheler J (2005) The electrocardiogram of human embryonic stem cell-derived cardiomyocytes. J Electrocardiol 38:166-170
Safran M, Dalah I, Alexander J, Rosen N, Stein TI, Shmoish M, Nativ N, Bahir I, Doniger T, Krug H, Sirota-Madi A, Olender T, Golan Y, Stelzer G, Harel A, Lancet D (2010) GeneCards version 3: the human gene integrator. Database (Oxford) 2010:baq020. doi:10.1093/database/baq020

Sawyer DB, Zuppinger C, Miller TA, Eppenberger HM, Suter TM (2002) Modulation of anthracycline-induced myofibrillar disarray in rat ventricular myocytes by neuregulin-1 beta and antierbB2: potential mechanism for trastuzumab-induced cardiotoxicity. Circulation 105:1551-1554

Sheppard R, Bedi M, Kubota T, Semigran MJ, Dec W, Holubkov R, Feldman AM, Rosenblum WD, McTiernan CF, McNamara DM (2005) Myocardial expression of Fas and recovery of left ventricular function in patients with recent-onset cardiomyopathy. $\mathrm{J}$ Am Coll Cardiol 46:1036-1042

Srinivasan S, Avadhani NG (2012) Cytochrome c oxidase dysfunction in oxidative stress. Free Radic Biol Med 53:1252-1263

Steel D, Hyllner J, Sartipy P (2009) Cardiomyocytes derived from human embryonic stem cells - characteristics and utility for drug discovery. Curr Opin Drug Discov Devel 12:133-140

Sundman-Engberg B, Tidefelt U, Gruber A, Paul C (1993) Intracellular concentrations of mitoxantrone in leukemic cells in vitro vs in vivo. Leuk Res 17:347-352

Sussman MA, HammAlvarez SF, Vilalta PM, Welch S, Kedes L (1997) Involvement of phosphorylation in doxorubicin-mediated myofibril degeneration-an immunofluorescence microscopy analysis. Circ Res 80:52-61

Szuts V, Menesi D, Varga-Orvos Z, Zvara A, Houshmand N, Bitay M, Bogats G, Virag L, Baczko I, Szalontai B, Geramipoor A, Cotella D, Wettwer E, Ravens U, Deak F, Puskas LG, Papp JG, Kiss I, Varro A, Jost N (2013) Altered expression of genes for Kir ion channels in dilated cardiomyopathy. Can J Physiol Pharmacol 91:648-656

Tafuri G, Trotta F, Leufkens HGM, Pani L (2013) Disclosure of grounds of European withdrawn and refused applications: a step forward on regulatory transparency. Br J Clin Pharmacol 75:1149-1151

Tonomura Y, Mori Y, Torii M, Uehara T (2009) Evaluation of the usefulness of biomarkers for cardiac and skeletal myotoxicity in rats. Toxicology 266:48-54

Wang FF, Guo YH, Yu HY, Zheng LB, Mi L, Gao W (2010) Growth differentiation factor 15 in different stages of heart failure: potential screening implications. Biomarkers 15:671-676

Yan XH, Morgan JP (2011) Neuregulin1 as novel therapy for heart failure. Curr Pharm Des 17:1808-1817

Zimmers TA, Jim XL, Hsiao EC, McGrath SA, Esquela AF, Koniaris LG (2005) Growth differentiation factor-15/macrophage inhibitory cytokine- 1 induction after kidney and lung injury. Shock 23:543-548 